\title{
DOI 10.26886/2414-634X.2(21)2018.3
}

UDC 621.436.004

\section{MATHEMATICAL MODEL OF DIAGNOSTICATION OF FUEL APPARATUS OF AUTOMOTIVE DIESELS}

\section{Baranovsky, Doctor of Technical Sciences, Professor}

Ternopil Ivan Puluj National Technical University, Ukraine, Ternopil

\section{A. Spirin, PhD in Technical Sciences, Associate Professor}

Vinnitsa National Agrarian University, Ukraine, Vinnitsa

Machinery and tractor park is an important link in agricultural production. From its efficient work depends to a large extent on reducing the cost of production, timely harvesting, transportation to its consumers, harvesting of forages and other production and household processes. Increase of productivity and economy of machine-tractor aggregates is possible due to increase of the resource and terms of trouble-free operation of machines. This is achieved through the development and implementation of effective methods and means of controlling the technical condition of machines. The article presents the mathematical model of diagnostics of fuel equipment of automotive diesel engines. A diagnostic matrix and a block diagram of its synthesis were constructed.

Key words: technical condition, maintenance, diagnostics of machines, matrix, fault, block diagram.

доктор технічних наук, профресор Барановський В. М., кандидат технічних наук, доцент Спірін А. В. Математична модель діагностування паливної апаратури автотракторних дизелів / Тернопільський національний технічний університет імені Івана Пулюя, Україна, Тернопіль; Вінницький національний аграрний університет, Україна, Вінниця

Машинно-тракторний парк $\epsilon$ важливою ланкою сільськогосподарського виробництва. Від його ефрективної роботи 
значною мірою залежить зниження собівартості продукції, своєчасне збирання врожаю, перевезення його споживачам, заготівля кормів та інші виробничі та господарсько-побутові процеси.

Підвищення продуктивності та економічності машиннотракторних агрегатів можливе за рахунок збільшення ресурсу $i$ термінів безвідмовної роботи машин. Це досягається иляхом розробки та впровадження ефрективних методів і засобів контролю технічного стану машин. У статті наведено математичну модель діагностування паливної апаратури автотракторних дизелів. Побудовано матрицю діагностування та блок-схему їі синтезу.

Ключові слова: технічний стан, технічне обслуговування, діагностика машин, матриця, несправність, блок-схема.

Вступ. Працездатність дизельного двигуна характеризується головним чином показниками потужності, витратою палива й оливи, пусковими якостями, забезпеченням санітарних вимог, що залежить від технічного стану паливної апаратури. Крім того, вказується, що за інших рівних умов саме паливна апаратура визначає ефективність робочого процесу дизеля.

На основі показників роботи машинно-тракторного парку встановлено, що паливна апаратура автотракторних дизелів $€$ найменш надійною і довговічною системою тракторів і автомобілів.

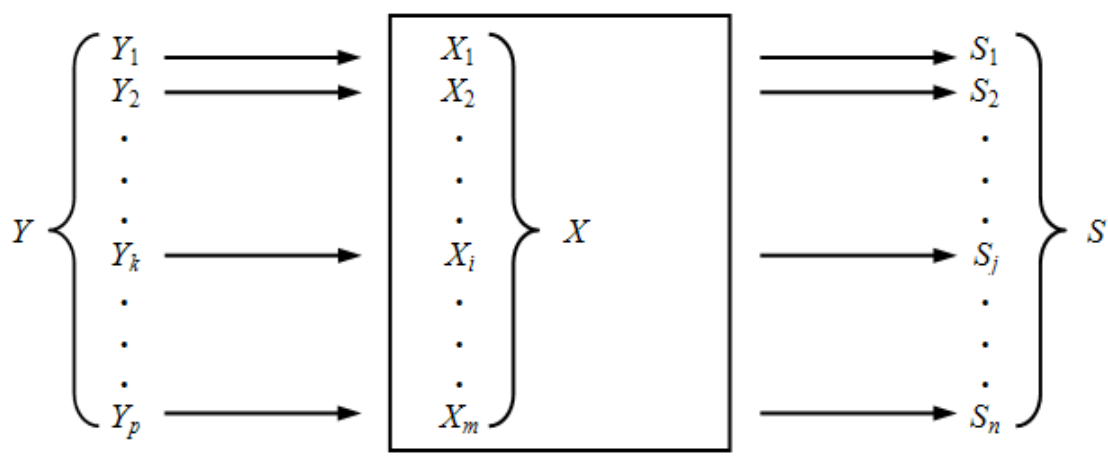

Рис. 1. Схема об'єкта діагностики 
Дослідженням діагностування паливних систем тракторів і автомобілів присвячена велика кількість робіт різних авторів [1, с. 126$129 ; 3$, с. $65-68 ; 6$, с. $82-84 ; 8$, c. $97-103 ; 9$, c. 42-45].

Найбільш універсальною моделлю об'єкта діагностики є його подання у вигляді «чорного ящика», вхідні та вихідні параметри якого мають кінцеву множину значень [5, 254-256].

Для представлення об’єкта діагностики у вигляді «чорного ящика» необхідно задати (рис. 1): кількість всіх вхідних дій $Y$ від стимулюючих пристроїв і зовнішнього середовища; кількість всіх вихідних ознак несправності $S$; кількість всіх несправностей об'єкта діагностування $X$; оператор $A$, який перетворює кількості $X$ та $Y$ в кількість $S$ :

$$
S=A\{Y, X\} .
$$

Враховуючи, що при діагностуванні елементи кількості $Y$ стабілізуються (або змінюються за заданим законом), вираз (1) можна записати у вигляді:

$$
S=A\{X\},
$$

де $A$ - заданий вигляд оператора.

Якщо несправність об'єкта діагностування $\left\{X_{i}\right\}$ віднести до вихідних параметрів автоматизованої системи, то діагностична задача сфрормулюється наступним чином: за відомим ознакам несправності $\left\{S_{j}\right\}$ визначити невідомі несправності об'єкта діагностування $\left\{X_{i}\right\}$.

Тоді за даними ознаками несправності $S_{1}, S_{2}, \ldots, S_{n}$, які отримано в результаті відповідних вимірювань, визначають технічний стан (несправності) об'єкта діагностування $X_{1}, X_{2}, \ldots, X_{m}$ за відомими функціональними залежностями між кожним діагностичним сигналом і структурними параметрами: 


$$
\left\{\begin{array}{l}
S_{1}=\varphi_{1}\left(x_{1}, x_{2}, \ldots, x_{m}\right) \\
S_{2}=\varphi_{2}\left(x_{1}, x_{2}, \ldots, x_{m}\right) \\
\ldots \ldots \ldots \ldots \ldots \ldots \ldots \ldots \ldots \\
S_{j}=\varphi_{j}\left(x_{1}, x_{2}, \ldots, x_{m}\right) \\
\ldots \ldots \ldots \ldots \ldots \ldots \ldots \ldots \ldots \\
S_{n}=\varphi_{n}\left(x_{1}, x_{2}, \ldots, x_{m}\right)
\end{array}\right.
$$

Система рівнянь (3) є математичною моделлю об'єкта діагностування, що має $m$ структурних параметрів і $n$ діагностичних сигналів.

Проте практичне використання такої аналітичної моделі обмежено за наявності наступних обставин: вигляд функцій $\varphi_{j}$ для більшості агрегатів і вузлів трактора не встановлений; якщо фрункція $\varphi_{j}$ не задовольняє умовам безперервності і диференціювання за кожним із своїх аргументів, що зазвичай має місце в реальних моделях, тоді рішення системи рівнянь (3) пов'язано з великими математичними труднощами; більшість діагностичних параметрів в реальному часі не можуть бути виражені у вигляді аналітичних функцій структурних параметрів.

Аналіз літературних та наукових джерел показав, що існуючі методи та засоби діагностування паливної апаратури не в достатній мірі відповідають сучасним вимогам щодо визначення їх поточного технічного стану. Вирішення проблеми можливе за рахунок розробки математичних моделей які описують процес функціонування паливної апаратури дизельного двигуна як об'єкта діагностування.

Формулювання мети статті та задач. Метою дослідження $є$ підвищення надійності фрункціонування паливної апаратури автотракторних дизелів шляхом розробки математичної моделі діагностування ії̈ вузлів та деталей, яка взаємо пов'язує несправності та ознаки їх несправностей. 
Рішення задачі автоматизації логічного процесу постановки діагнозу несправності технічних систем зведено до розробки моделей тракторних і автомобільних агрегатів як об'єктів діагностування. Розроблені моделі повинні описувати на одному математичному рівні взаємозв'язки між можливими несправностями та значеннями діагностичних параметрів [4, с. 32, 5, с. 321].

Математична модель об'єкта діагностування повинна бути представлена у вигляді аналітичних, логічних, статистичних, графрічних і взагалі будь-яких якісних співвідношень, які пов'язують вихідні параметри об'єкта діагностування 3 його вхідними і внутрішніми параметрами.

Викладення основного матеріалу статті. У ряді робіт 3 технічного діагностування тракторів і автомобілів взаємозв'язок між можливими несправностями агрегатів і систем трактора та ознаками цих несправностей описується у вигляді діагностичних матриць $[5$, с. 49; 7, с. 132].

У складеній матриці (табл.) позначимо наступні несправності паливної апаратури автотракторних дизелів: $x_{1}$ - підсмоктування повітря в систему паливоподачі; $x_{2}$ - порушення параметрів впорскування палива форсунками; $\quad x_{3}$ - паливний насос високого тиску не забезпечує робочий тиск впорскування під час пуску двигуна; $x_{4}$ - понижений тиск палива, яке подається до паливного насоса високого тиску; $x_{5}$ - кут початку подачі палива менше номінального; $x_{6}$ - кут початку подачі палива більше номінального; $x_{7}$ нерівномірність подачі палива секціями паливного насоса високого тиску; $x_{8}$ - збільшена максимальна подача палива паливним насосом високого тиску; $x_{9}$ - занижена максимальна подача палива паливним насосом високого тиску; $x_{10}$ - забруднення фрільтруючих елементів; $x_{11}$ - поломка пружин або негерметичність нагнітальних клапанів; $x_{12}$ 
зависання плунжера паливного насоса високого тиску; $x_{13}$ спрацювання плунжерної пари.

Таблиця

\section{Матриця діагностування паливної апаратури автотракторних} двигунів

\begin{tabular}{|c|c|c|c|c|c|c|c|c|c|c|}
\hline $\begin{array}{c}\text { Несправніст } \\
\text { ь }\end{array}$ & \multicolumn{10}{|c|}{ Ознака несправності } \\
\cline { 2 - 12 } & $S_{1}$ & $S_{2}$ & $S_{3}$ & $S_{4}$ & $S_{5}$ & $S_{6}$ & $S_{7}$ & $S_{8}$ & $S_{9}$ & $S_{10}$ \\
\hline$x_{1}$ & 1 & 1 & 0 & 1 & 0 & 0 & 0 & 1 & 1 & 0 \\
\hline$x_{2}$ & 1 & 1 & 1 & 1 & 1 & 0 & 1 & 0 & 1 & 1 \\
\hline$x_{3}$ & 1 & 1 & 0 & 1 & 0 & 0 & 0 & 0 & 1 & 0 \\
\hline$x_{4}$ & 1 & 1 & 0 & 1 & 0 & 0 & 0 & 1 & 1 & 0 \\
\hline$x_{5}$ & 1 & 1 & 0 & 0 & 1 & 0 & 1 & 0 & 1 & 1 \\
\hline$x_{6}$ & 0 & 1 & 0 & 0 & 0 & 0 & 1 & 0 & 1 & 1 \\
\hline$x_{7}$ & 0 & 0 & 1 & 1 & 0 & 0 & 0 & 0 & 1 & 0 \\
\hline$x_{8}$ & 0 & 0 & 0 & 0 & 0 & 1 & 0 & 0 & 0 & 1 \\
\hline$x_{9}$ & 0 & 0 & 0 & 0 & 0 & 0 & 0 & 0 & 1 & 0 \\
\hline$x_{10}$ & 1 & 0 & 0 & 1 & 0 & 0 & 0 & 0 & 0 & 0 \\
\hline$x_{11}$ & 0 & 0 & 1 & 0 & 0 & 0 & 0 & 0 & 1 & 0 \\
\hline$x_{12}$ & 0 & 0 & 0 & 1 & 0 & 0 & 0 & 0 & 1 & 0 \\
\hline$x_{13}$ & 1 & 0 & 0 & 0 & 0 & 0 & 0 & 0 & 0 & 0 \\
\hline
\end{tabular}

Позначимо ознаки вказаних несправностей таким чином: $S_{1}$ холодний двигун не запускається; $S_{2}-$ двигун важко запускається; $S_{3}-$ нестійка робота двигуна; $S_{4}-$ двигун працює з перебоями; $S_{5}-$ чорний дим за будь-якої частоти обертання двигуна; $S_{6}-$ чорний дим за номінальної частоти обертання двигуна; $S_{7}$ - стукіт двигуна; $S_{8}$ самовільна зупинка двигуна; $S_{9}$ - не забезпечується номінальна потужність двигуна; $S_{10}-$ підвищена витрата палива.

Кожна несправність характеризується певною комбінацією значень її ознак, які можуть приймати два умовних значення «0» і «1».

На перетині i-го рядка та ј-го стовпця записуємо «1», якщо за наявності i-ої несправності спостерігається вихід ј-ої ознаки з області її допустимих значень. У протилежному випадку записуємо «0». 
Для синтезу такої матриці необхідно нескінченну кількість технічних станів об'єкта замінити кінцевою множиною технічних станів, кожне з яких пов'язано з певною несправністю (або їх комбінацією), або з працездатним станом (рис. 2).

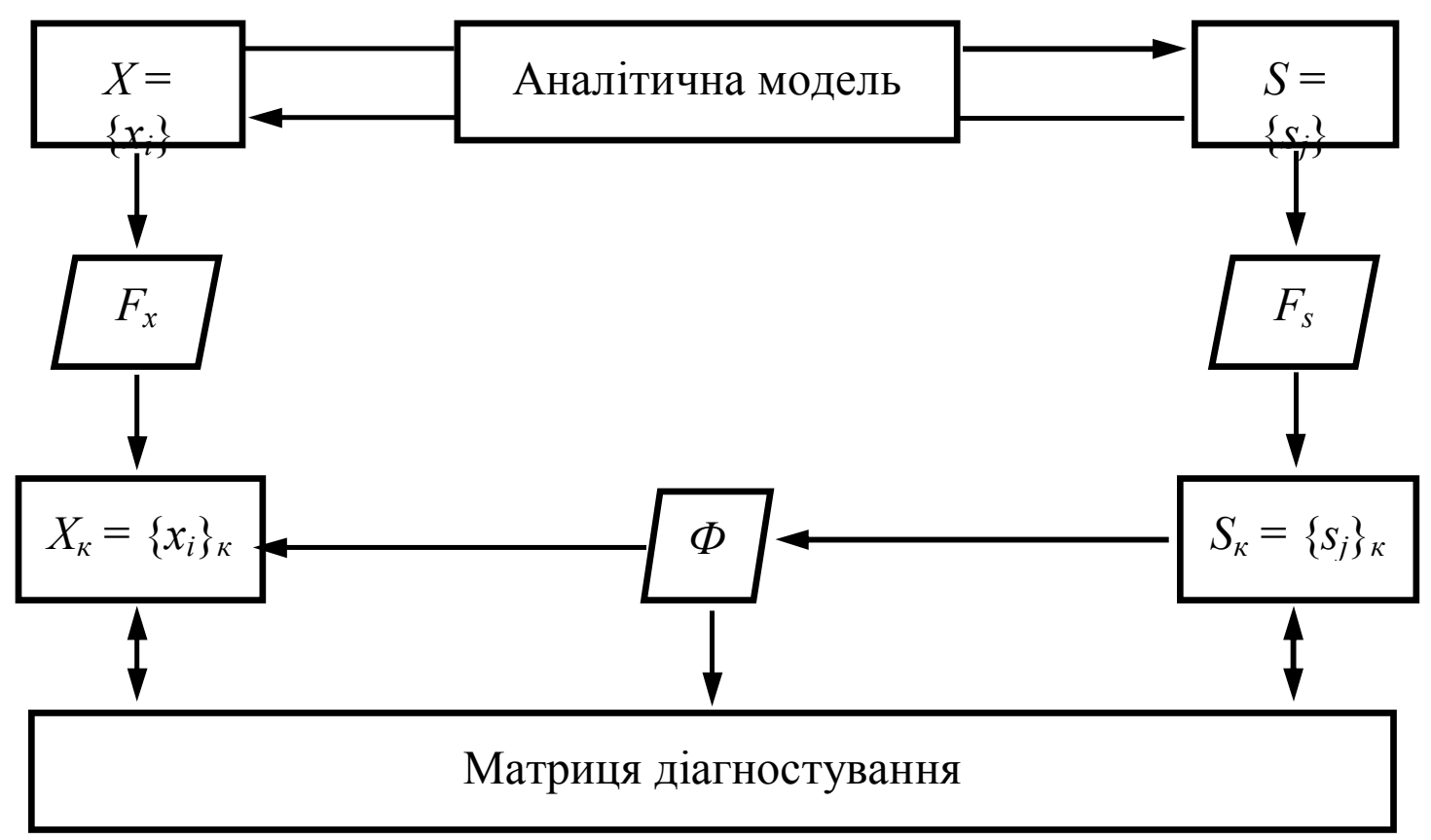

Рис 2. Блок-схема синтезу матриці діагностування: $X=\left\{x_{i}\right\}-$ нескінченна кількість технічних станів об'єкта; $X_{K}=\left\{x_{i}\right\}_{K}-$ кінцева кількість технічних станів; $S=\left\{s_{j}\right\}-$ нескінченна множина ознак технічних станів об'єкта;

$S_{K}=\left\{s_{j}\right\}_{K}-$ кінцева множина ознак технічних станів обкат; $F_{x}-$ оператор, який перетворює кількість $\left\{x_{i}\right\}$ в кількість $\left\{x_{i}\right\}_{\kappa} ; F_{s}-$ оператор, який перетворює кількість $\left\{s_{j}\right\}$ в кількість $\left\{s_{j}\right\}_{\kappa} ; \Phi-$ оператор, який перетворює кількість технічних станів об'єкта в кількість діагностичних параметрів

Таке перетворення може бути записано у вигляді

$$
\left\{x_{i}\right\}_{\kappa}=F_{x}\left\{x_{i}\right\},
$$

де $\left\{x_{i}\right\}$ - множина ознак технічних станів об'єкта діагностування, кожна 3 яких може приймати в загальному випадку нескінченну кількість значень; $\left\{x_{i}\right\}_{\kappa}$ - кінцева множина ознак технічних станів об'єкта діагностування, кожна з яких може приймати лише два умовних значення «0» і «1», які відповідають відсутності та наявності $i$-ої 
несправності; $i=1,2, \ldots, m ; F_{x}$ - оператор, який перетворює кількість $\left\{x_{i}\right\}$ в кількість $\left\{x_{i}\right\}_{\kappa}$ наступним чином: для будь-якого $i$-го параметру $x_{i}$ присвоюється значення «0», якщо величина лежить в області допустимих значень, в протилежному випадку присвоюється значення «1».

Перетворення нескінченної кількості значень параметрів вихідних процесів в кінцеве значення діагностичних параметрів записано у вигляді

$$
\left\{s_{j}\right\}_{K}=F_{s}\left\{s_{j}\right\}
$$

де $\left\{s_{j}\right\}$ - кількість ознак вихідних процесів, кожна з яких може приймати в загальному випадку нескінченну кількість значень в певному інтервалі; $\left\{s_{j}\right\}_{\kappa}$ - кінцева кількість діагностичних ознак, кожна з яких може приймати тільки два умовних значення «0» і «1»; $j=1,2 \ldots, n ; F_{s}-$ оператор, що перетворює кількість $\left\{s_{j}\right\}$ в кількість $\left\{s_{j}\right\}_{\kappa}$ наступним чином: будь-якій $j$-ій ознаці $s_{j}$ присвоюється умовне значення «0», якщо величина лежить в області значень, що відповідають справного стану об'єкта діагностування, в протилежному випадку присвоюється значення « $1 »$.

У результаті проведених перетворень отримано два кінцевих значення $\left\{x_{i}\right\}_{\kappa} \mathrm{i}\left\{s_{j}\right\}_{\kappa}$, елементи яких певним чином пов'язані один 3 одним:

$$
\left\{s_{j}\right\}_{K}=\Phi\left\{x_{i}\right\}_{\kappa},
$$

де $Ф$ - оператор, що перетворює кількість технічних станів об'єкта в кількість діагностичних параметрів.

Перетворення (6) відображає функціонування будь-якого технічного об'єкта як перетворювача кількості структурних параметрів у кількість діагностичних параметрів і є модифрікацією моделі (1).

Перетворення (6) можна розгорнути за допомогою системи (3). Система рівнянь (3) пов'язує кожну ознаку несправності $S_{j}$ з усіма 
структурними параметрами об'єкта діагностування, що відображає зв'язки між структурними параметрами і діагностичними сигналами.

Матриця діагностування, як модель об'єкта діагностування показує, що вона $є$ по суті табличною формою запису системи рівнянь (1). Параметр $S_{1}$ в матриці діагностування паливної апаратури автотракторних дизелів можна розглядати як двозначну булеву функцію, яка залежить від аргументів $x_{1}, x_{2}, x_{3}, x_{4}, x_{5}, x_{10}, x_{13}$.

Булева фрункція залежить від аргументу $x_{1}$, якщо має місце співвідношення $\varphi\left(x_{1}, x_{2}, \ldots, x_{i-1}, 0, x_{i+1}, \ldots, x_{m}\right) \neq \varphi\left(x_{1}, x_{2}, \ldots, x_{i-1}, 1, x_{i+1}, \ldots, x_{m}\right), \quad$ тобто $S_{1}$ істотно залежить тільки від $x_{1}, x_{2}, x_{2}, x_{4}, x_{5}, x_{10}, x_{13}$.

Залежність $S_{1}=\varphi_{1}\left(x_{1}, x_{2}, x_{3}, x_{4}, x_{5}, x_{10}, x_{13}\right)$ записано у вигляді функції логічного додавання (диз'юнкція): $S_{1}=x_{1}+x_{2}+x_{2}+x_{4}+x_{5}+x_{10}+$ $x_{13}$.

Відповідний аналіз інших ознак несправностей дозволяє записати систему рівнянь (3) для даної матриці діагностування паливної апаратури автотракторних дизелів у вигляді:

$$
\left\{\begin{array}{l}
S_{1}=x_{1}+x_{2}+x_{3}+x_{4}+x_{5}+x_{10}+x_{13} \\
S_{2}=x_{1}+x_{2}+x_{3}+x_{4}+x_{5}+x_{6} \\
S_{3}=x_{2}+x_{7}+x_{11} ; \\
S_{4}=x_{1}+x_{2}+x_{3}+x_{4}+x_{7}+x_{10}+x_{12} ; \\
S_{5}=x_{2}+x_{5} ; \\
S_{6}=x_{8} \\
S_{7}=x_{2}+x_{5}+x_{6} ; \\
S_{8}=x_{1}+x_{4} ; \\
S_{9}=x_{1}+x_{2}+x_{3}+x_{4}+x_{5}+x_{6}+x_{7}+x_{11}+x_{12}+x_{14} \\
S_{10}=x_{2}+x_{5}+x_{6}+x_{8}
\end{array}\right.
$$

Всі послідовні перетворення, що призводять до синтезу моделі об'єкта діагностування у вигляді діагностичної матриці, наочно представлено на блок-схемі (рис. 2). 
У тому випадку, коли модель об'єкта діагностування представлена у вигляді діагностичної матриці (табл.), діагностична задача сорормулюється наступним чином.

За даними ознаками несправностей $S_{1}, S_{2}, \ldots, S_{n}$, які отримано під час діагностичного обстеження, необхідно визначити несправності $x_{1}$, $x_{2}, \ldots, x_{m}$, які виникають під час перевірки за умови, що відомі функціональні залежності між діагностичними параметрами і всіма структурними параметрами, які задано у вигляді діагностичної матриці, або наведеної системи рівнянь (7). Кожен структурний параметр і кожен діагностичний параметр приймає тільки два значення: «0» $\mathrm{i}$ «1».

Очевидно що для вирішення діагностичної задачі необхідне зворотне перетворення кількості діагностичних параметрів в кількість структурних параметрів, тому що під час постановки діагнозу несправностей відомими є тільки значення діагностичних параметрів.

У загальному вигляді зворотне перетворення можна представити виразом $\left\{x_{i}\right\}_{\kappa}=\Phi^{-1}\left\{s_{j}\right\}_{\kappa}$, або в розгорнутому вигляді:

$$
\left\{\begin{array}{l}
x_{1}=f_{1}\left(S_{1}, S_{2}, \ldots, S_{n}\right) ; \\
x_{2}=f_{2}\left(S_{1}, S_{2}, \ldots, S_{n}\right) ; \\
x_{m}=f_{m}\left(S_{1}, S_{2}, \ldots, S_{n}\right)
\end{array}\right.
$$

Вигляд функцій $f_{m}$ можна встановити в кожному конкретному випадку на основі наступних міркувань.

У діагностичній матриці (табл.) розглянемо окремо один із стовбців, наприклад, перший. 3 матриці видно, що наявність несправності $x_{1}$ викликає одночасно вихід п'яти її ознак $S_{1}, S_{2}, S_{4}, S_{8}$ та $\mathrm{S}_{9}$ з області їх допустимих значень. Значення інших діагностичних параметрів при наявності тільки несправності $x_{1}$ залишаються в межах норми.

Тоді $x_{1} €$ булевою функцією, або в даному випадку кон'юнкція (або функцією логічного множення): $x_{1}=S_{1} S_{2} S_{4} S_{8} S_{9}$. 
Відповідний аналіз всіх інших стовпців розглянутої матриці дозволяє зворотне перетворення (3) записати в вигляді системи булевих функцій:

$$
\left\{\begin{array}{l}
x_{1}=S_{1} S_{2} S_{4} S_{8} S_{9} ; \\
x_{2}=S_{1} S_{2} S_{3} S_{4} S_{5} S_{7} S_{9} S_{10} ; \\
x_{3}=S_{1} S_{2} S_{4} S_{9} ; \\
x_{4}=S_{1} S_{2} S_{4} S_{8} S_{9} ; \\
x_{5}=S_{1} S_{2} S_{5} S_{7} S_{9} S_{10} ; \\
x_{6}=S_{2} S_{7} S_{9} S_{10} ; \\
x_{7}=S_{3} S_{4} S_{9} ; \\
x_{8}=S_{6} S_{10} ; \\
x_{9}=S_{9} ; \\
x_{10}=S_{1} S_{4} ; \\
x_{11}=S_{3} S_{9} ; \\
x_{12}=S_{4} S_{9} ; \\
x_{13}=S_{13}
\end{array} ;\right.
$$

При цьому процес постановки діагнозу несправностей на основі моделі об'єкта діагностування, вираженої у вигляді діагностичної матриці, складається з наступних етапів:

- шляхом відповідних вимірювань і перетворень встановлюються ознаки всіх несправностей $S_{1}, S_{2}, \ldots, S_{n}$;

- значення діагностичних параметрів підставляються в систему булевих функцій (8);

- обчислюються значення всіх булевих фрнкцій несправностей $x_{i}(i$ $=1,2, \ldots, m)$ причому якщо $x_{i}=1$, то в об'єкті $€ i$-та несправність.

Таким чином, згідно до блок-схеми синтезу матриці діагностування (рис. 2) можна сформулювати умову здійснення діагностування в загальному вигляді: для здійснення діагностування достатньо, щоб зворотне перетворення кількості ознак несправностей у кількість структурних параметрів (несправностей) об'єкта було однозначним.

Якщо в процесі синтезу діагностичної матриці не виконана ця умова і в системі (8) є дві або більше рівних функцій, тоді перелік 
діагностичних параметрів необхідно доповнити новим параметром, який увійшов би в якості додаткового аргументу тільки в одну 3 розглянутих рівних функцій.

Висновки. Розроблена математична модель діагностування паливної апаратури автотракторних двигунів як об'єкт діагностики дозволяє виявити несправності залежно від їх ознак, що значно підвищує термін експлуатації тракторів і автомобілів.

\section{תimepamypa:}

1. Аллилуев B. А. Техническая диагностика тракторов и зерноуборочных комбайнов / В. А. Аллилуев, Н. С. Ждановский, А. В. Николаенко. - М.: Колос, 1978. - 287 с.

2. Ананьин А. Д. Диагностика и техническое обслуживание машин / $A$.

Д. Ананьин, В. М. Михлин, И. И. Габитов. - М.: Издательский центр «Академия», 2008. - 432 с.

3. Ждановский Н. С. Надежность и долговечность автотракторных двигателей / Н. С. Ждановский, А. В. Николаенко. - Л.: Колос, 1981. 295 c.

4. Малкин В. С. Техническая диагностика / В. С. Малкин. - СПб.: Издательство «Лань», 2013. - 272 с.

5. Маслов Г. Г. Техническая эксплуатация МТП / Г. Г. Маслов, А. П. Карабаницкий, Е.А. Кочкин. - Краснодар: Изд-во Кубанского государственного аграрного университета, 2008. - 142 с.

6. Николаенко А. В. Повышение эфффективности использования тракторных дизелей в сельском хозяйстве / А. В. Николаенко, В. Н. Хватов. - Л.: Агропрмиздат, 1986. - 191 с.

7. Пучин Е. А. Техническое обслуживание и ремонт тракторов / Е. А. Пучин, Л. И. Кушнарёв, Н. А. Петрищев. - М.: Издательский чентр «Академия», 2007. - 208 с. 
8. Сельцер A. A. Обнаружение и устранение неисправностей тракторов / А. А. Сельцер. - М.: Агропромиздат, 1987. - 271 с.

9. Станиславский Л. В. Техническое диагностирование дизелей / Л.

В. Станиславский. - К.: Вища школа, 1983. - 136 с.

\section{References:}

1. Allyluev V. A. Tekhnycheskaia dyahnostyka traktorov $y$ zernouborochnыkh kombainov / V. A. Allyluev, N. S. Zhdanovskyi, A. V. Nykolaenko. - M.: Kolos, 1978. - 287 s.

2. Ananyn A. D. Dyahnostyka y tekhnycheskoe obsluzhyvanye mashyn / A. D. Ananyn, V. M. Mykhlyn, Y. Y. Habytov. - M.: Yzdatelskyi tsentr «Akademyia», 2008. - 432 s.

3. Zhdanovskyi N. S. Nadezhnost y dolhovechnost avtotraktornykh dvyhatelei / N. S. Zhdanovskyi, A. V. Nykolaenko. - L.: Kolos, 1981. - 295 S.

4. Malkyn V. S. Tekhnycheskaia dyahnostyka / V. S. Malkyn. - SPb.: Yzdatelstvo «Lan», 2013. - 272 s.

5. Maslov H. H. Tekhnycheskaia ekspluatatsyia MTP / H. H. Maslov, A. P. Karabanytskyi, E.A. Kochkyn. - Krasnodar: Yzd-vo Kubanskoho hosudarstvennoho ahrarnoho unyversyteta, 2008. - $142 \mathrm{~s}$.

6. Nykolaenko A. V. Povyshenye effektyvnosty yspolzovanyia traktornykh dyzelei $v$ selskom khoziaistve / A. V. Nykolaenko, V. N. Khvatov. - L.: Ahroprmyzdat, 1986. - 191 s.

7. Puchyn E. A. Tekhnycheskoe obsluzhyvanye y remont traktorov / E. A. Puchyn, L. Y. Kushnarëv, H. A. Petryshchev. - M.: Yzdatelskyi tsentr «Akademyia», 2007. - 208 s.

8. Seltser A. A. Obnaruzhenye y ustranenye neyspravnostei traktorov / A.

A. Seltser. - M.: Ahropromyzdat, 1987. - 271 s.

9. Stanyslavskyi L. V. Tekhnycheskoe dyahnostyrovanye dyzelei / L. V. Stanyslavskyi. - K.: Vyshcha shkola, 1983. - 136 s. 